\title{
Arbitraje de inversión en el TLC Colombia - Estados Unidos: efectos frente a los derechos socioeconómicos de los colombianos. Una mirada doctrinal ${ }^{1}$
}

\author{
Sara Patricia Guzmán Suárez²
}

En las prácticas del mundo globalizado, el arbitraje de inversión es un tema que requiere de amplio conocimiento por parte de diferentes sectores, tanto a nivel internacional como nacional. Los gobiernos, y en especial los funcionarios encargados de la inversión externa, necesitan estar en consonancia, no solo con las tendencias actuales de la negociación de inversión como tal, sino, para el caso concreto de esta investigación, con la solución de los conflictos de inversión.

1 Este artículo de investigación hace parte de los trabajos para la tesis doctoral sobre «El Arbitraje de inversión frente al Art. 11 del Pacto Internacional de los Derechos Económicos, Sociales y Culturales». USTA, Bogotá.

2 Abogada de la Universidad Santo Tomás, Bogotá; especialista en Derecho Procesal de la Universidad Libre, Bogotá; magíster en Leyes de la Universidad de Illinois Urbana (Champaign, Estados Unidos); estudiante del Doctorado en Derecho, Universidad Santo Tomás, Bogotá; docente de Derecho Internacional y MASC en la Universidad Pontificia Bolivariana, Secc. Bucaramanga; miembro grupo CIPJURIS, directora del Centro de Conciliación UPB. Correo electrónico: sara.guzman@upb.edu.co 
Esa solución de disputas necesariamente tendrá que tomar en cuenta no solo el cumplimiento de las normas internacionales respectivas, sino la realidad de los países en los que se efectúan las inversiones; aspecto sobre el que existe un vacío e insuficiencia de estudio, máxime cuando algunos países, si bien cuentan con acuerdos que implican acudir al arbitraje, no han tenido todavía la experiencia de avocarse a una demanda.

El tema aquí propuesto comprende un estudio concreto, desde los derechos económicos, sociales y culturales (DESC), sobre las aristas implicadas en el arbitraje en materia de inversiones de manera general, y busca contribuir con la estructuración de elementos de análisis sobre el actuar de los países, tanto de los destinatarios de inversión como de los de origen de los inversores, a la hora de la resolución de disputas sobre estos temas.

Se considera por parte de algunos sectores que la coexistencia entre inversión extranjera y buen nivel de vida de los habitantes del Estado anfitrión no es imposible, pero para ello se necesita investigar sobre las relaciones que subyacen cuando se presentan conflictos derivados de la necesidad de recurrir a capital extranjero, sobretodo en el caso de los países en desarrollo, y los niveles de afectación frente a los derechos de inversores y personas del común, y la aplicación de las regulaciones pertenecientes a unos y otros sectores que conforman subsistemas en el ámbito del derecho internacional.

Por lo dicho anteriormente y dada la función de administrar justicia que se cumple en los arbitrajes de inversión, resulta determinante para un país como Colombia analizar las implicaciones de la inclusión de ciertas garantías para los inversores extranjeros (como es el caso de este tipo de arbitraje) dentro de tratados de inversión que suscriba. Si lo que se busca es el desarrollo, so pretexto de conseguirlo, mal puede diseñarse y aceptarse instrumentos internacionales que vulneren los derechos de los ciudadanos, pues lo que se estaría obteniendo sería un efecto completamente contrario al buscado.

Para hacer frente a esta posibilidad, se hace necesario conocer sobre las implicaciones del arbitraje de inversión frente al Pacto Internacional de los Derechos Sociales, Económicos y Culturales, Pidesc (art. 11), y las relaciones entre derechos y sistemas que plantea la presente investigación.

La presente investigación resultará oportuna en la medida en que al explicar las relaciones entre el aludido arbitraje de inversión y el Pidesc (art. 11), en el contexto del Tratado de Libre Comercio, se pondrán sobre el plano actual las necesidades particulares que se derivan de esta relación, de donde sería posible deducir acciones encaminadas a una mejor representación estatal en el marco del Centro Internacional de Arreglo de Diferencias relativas a Inversiones (Ciadi) y de los demás centros de arbitraje especializados en la materia, y que podrían ser utilizadas a la hora de revisar aspectos de vacíos legales domésticos relativos a las inversiones extranjeras. 
El Acuerdo de Promoción Comercial entre la República de Colombia y los Estados Unidos de América, o Tratado de Libre Comercio TLC, es un tema complejo que ha generado pronunciamientos enfrentados, emitidos por parte de diversos sectores en nuestro país, especialmente en lo que atañe a sus implicaciones frente a los derechos de los colombianos. Este punto en específico ha suscitado, no solo en Colombia sino en otros países latinoamericanos donde se han implementado TLC, la polarización de posiciones.

En este orden de ideas, el arbitraje de inversión, como mecanismo incluido en el capítulo X del TLC de Colombia con los Estados Unidos, cuenta con defensores y adversarios, dependiendo del plano del control jurídico (Silva, 2002) con el que se enfoque.

El aludido mecanismo ocupa un papel central en la presente investigación desde el punto de vista de las consideraciones particulares de sus repercusiones frente a los derechos económicos y sociales de los colombianos, los cuales podrían resultar afectados negativamente con la aplicación del mismo, en el contexto de la resolución de controversias generadas con ocasión del Tratado.

Para la elaboración de la presente investigación partiré de la contextualización del mecanismo a través de la construcción del marco jurídico, incluyendo una breve reseña histórica y doctrinal que indique en primer lugar, y para nuestros efectos, qué es el TLC y qué es el arbitraje de inversión, para luego pasar a exponer la relación entre las dos figuras y plantear las posiciones en pro y en contra frente a estas dos instituciones.

Así mismo, dejaré sentadas las bases que serán consideradas en un próximo avance respecto al tema de los derechos económicos y sociales que podrían verse conculcados con la práctica del mencionado mecanismo y las potenciales causas de ello, a partir de las experiencias latinoamericanas.

En la misma línea, y con el propósito de esbozar sugerencias frente a la problemática planteada, en el desarrollo de esta investigación busco anticipar algunas dificultades prácticas que podría implicar el desarrollo de esta clase de arbitraje en Colombia. Por último, al final de toda la investigación, pretendo plantear soluciones basadas en el análisis propio y en antecedentes de otros Estados en la misma situación.

El abordaje de este tema implica un reto, teniendo en cuenta que estos asuntos, por su implementación relativamente reciente, no gozan de muchos antecedentes a nivel doméstico, por lo tanto es necesario recurrir a casos fuera de nuestro territorio nacional. 


\section{NEGOCIACIÓN Y APROBACIÓN DEL TLC COLOMBIA-EE.UU.}

\section{Reseña histórica}

Washington D.C. fue la ciudad sede de la firma del Acuerdo de Promoción Comercial, o TLC, entre la República de Colombia y los Estados Unidos de América. Según el Ministerio de Comercio, Industria y Turismo (2013), los documentos pertinentes fueron suscritos por los dos gobiernos el 22 de noviembre de 2006, en la capital estadounidense. El tratado fue aprobado en la Cámara y en el Senado colombianos el 5 y 7 de junio de 2007 respectivamente. Finalmente, fue sancionado por parte del presidente de la República y se convirtió en la Ley 1143 del 4 de Julio de 2007. De otra parte, con la Sentencia C-750 la Corte Constitucional se pronunció favorablemente sobre la exequibilidad tanto del tratado mismo como de la ley aprobatoria de este. El proceso culminó con un pronunciamiento en el mismo sentido respecto del llamado "protocolo modificatorio" y su ley aprobatoria, esto es la Ley 1166 de 2007, que fueron declarados exequibles por la Sentencia C-751 del 24 de Julio de 2008.

Un punto digno de destacar es el largo tiempo que tomaron las negociaciones de nuestro TLC y la explicación radica precisamente en las posiciones encontradas de los diversos sectores, tanto a nivel colombiano como del país del norte, asunto en el que se ahondará más adelante.

La revista Portafolio (2006) afirma que el camino para el TLC aquí referido, que para Colombia duró 14 rondas de negociación, comenzó de manera incipiente en abril de 2003 frente al fracaso del ALCA (Área de Libre Comercio de las Américas), proyecto impulsado por Estados Unidos. Para esa época, el entonces presidente Álvaro Uribe Vélez sugirió al presidente Bush suscribir un TLC con Colombia, idea que tuvo acogida. Se planteó la misma posibilidad para Ecuador y Perú, países que junto con Colombia estaban cobijados por la Atpdea (Ley de Preferencias Arancelarias Andinas y Erradicación de la Droga o Andean Trade Promotion and Drug Eradication Act), pero no se incluyó a Venezuela ni a Bolivia. El gobierno colombiano buscaba abrirle posibilidades a los productos de su tierra en el gran mercado de los Estados Unidos. Las negociaciones duraron más de lo deseado; un punto álgido fue el relativo al sector agropecuario nacional que no alcanzaba a competir con los subsidios de sus homólogos norteamericanos y que a su vez era objeto de talanqueras de carácter sanitario y fitosanitario para llevar sus productos a los Estados Unidos.

Grupos colombianos de académicos, diferentes ONG, miembros de la Iglesia católica y casas farmacéuticas colombianas se mostraron en desacuerdo con las negociaciones, estos últimos en especial en lo referente a la propiedad intelectual de los medicamentos. 
Ecuador se quedó fuera del proceso por problemas internos que terminarían con el cambio del presidente de ese país. Perú, por su parte, terminó las negociaciones en 2005.

Luego de la firma de nuestro TLC se siguieron generando situaciones complejas por cuenta de asuntos sindicales y de derechos humanos en Colombia y al interior de la política de los Estados Unidos.

\section{MATERIAS OBJETO DEL TLC COLOMBIA EE.UU.}

El acuerdo cuenta con 23 capítulos que contienen los lineamientos generales y algunas precisiones de carácter particular, como por ejemplo aspectos sobre temas fitosanitarios.

El factor diferenciador en los TLC son sus anexos, los cuales se formulan para cada caso específico, en relación con los países participantes.

De acuerdo con una clasificación proveniente del gobierno colombiano, el TLC con los Estados Unidos está compuesto por temas diversos y complejos, así: disposiciones y definiciones generales, trato nacional y acceso a mercados, textiles y vestido, reglas de origen, procedimientos aduaneros, medidas sanitarias y fitosanitarias, obstáculos técnicos al comercio, defensa comercial, contratación pública, inversiones, comercio de servicios transfronterizos, servicios financieros, política de competencia, telecomunicaciones, comercio electrónico, derechos de propiedad intelectual, aspectos laborales, medio ambiente, transparencia, administración, solución de controversias, excepciones y disposiciones finales. Los temas pertinentes a esta investigación, aquí enumerados, serán objeto de estudio posteriormente.

\section{CONTEXTO DEL TLC Y EL ARBITRAJE DE INVERSIÓN}

A continuación se definen los elementos principales del presente estudio, arbitraje de inversión y TLC, para luego pasar al análisis de sus efectos respecto a los derechos económicos y sociales de los colombianos, que se planteará en otro capítulo de investigación.

\section{TLC}

$\mathrm{Al}$ abordar este tema, se recurre a una definición general para introducir tanto las posiciones enfrentadas como los posibles efectos que de ellas se puedan derivar. El 
concepto emitido por el gobierno peruano, a través de su Ministerio de Comercio y Turismo (2013), indica que «un tratado de libre comercio (TLC) es un acuerdo comercial vinculante que suscriben dos o más países para acordar la concesión de preferencias arancelarias mutuas y la reducción de barreras no arancelarias al comercio de bienes y servicios».

Generalmente este tipo de tratados o convenios desarrollan temas de beneficio para las partes intervinientes, como acceso a nuevos mercados, normatividad comercial relativa a propiedad intelectual, competencia, servicios financieros, telecomunicaciones, comercio electrónico, asuntos laborales, etc.

Los TLC, por su naturaleza, deben brindar seguridad a la inversión extranjera, para ello (entre otros aspectos), incluyen, según Zuleta (2007), los denominados estándares mínimos de protección. Estos estándares configuran obligaciones internacionales, no solo en cuanto a la inversión misma, sino también respecto a sus rendimientos. Su interpretación se efectúa mediante los laudos arbitrales que pasan a ser precedentes.

En el caso del TLC Colombia-EE.UU., se estipulan los siguientes estándares de protección a la inversión: el trato nacional, el trato de nación más favorecida, el nivel mínimo de trato, el tratamiento en caso de contienda, la prohibición de la expropiación sin indemnización y la prohibición de requisitos de desempeño.

Estos estándares se tendrán en cuenta a la hora de revisar si su práctica puede resultar nociva para los colombianos en lo que se refiere a los derechos económicos y sociales.

\section{ARBITRAJE DE INVERSIÓN}

Para hablar de este mecanismo es preciso concretar qué se entiende por arbitraje de inversión, tema que no ha gozado de unanimidad de criterio pero que es relevante desde el punto de vista práctico por dos razones: lo que no sea inversión queda por fuera del tratado y, de otra parte, solo si la controversia se refiere a una inversión, los tribunales arbitrales tendrán jurisdicción (Zuleta, 2007).

En el TLC entre Colombia y EE.UU. inversión se define como:

Todo activo de propiedad de un inversionista, controlado por el mismo, directa o indirectamente, que tenga las características de una inversión, incluyendo características tales como el compromiso de capitales $\mathrm{u}$ otros recursos, la expectativa de obtener ganancias o utilidades o la asunción de riesgo (capítulo X, numeral 10.28). 
En este mismo apartado se esboza una lista de asuntos considerados como inversión, utilizando la palabra «incluyen», por lo que la doctrina considera que esta enumeración no es exhaustiva. Entre dichas formas de inversión se pueden citar: empresas, acciones, bonos, obligaciones, instrumentos de deuda y contratos llave en mano, de construcción, de gestión y de producción. De la misma forma se enuncia lo relativo a la propiedad intelectual y a otros derechos de propiedad tanto en bienes tangibles como intangibles, muebles e inmuebles y lo relacionado con hipotecas y arrendamientos.

Esta definición apareja tres requerimientos: 1) que sea un activo 2) que el inversionista tenga el control directo o indirecto de la misma, no necesariamente debe ser el propietario, y 3) que tenga características de inversión (Zuleta, 2007).

Pero ¿cuáles son esas características? Un sector de la doctrina encabezado por Schereuer (Zuleta, 2007) las ha sintetizado así: 1) Duración: que sean de largo plazo. Las vinculaciones de capitales a corto plazo como una simple compraventa que se da en un solo acto no constituyen inversión. 2) Utilidad: Que exista una expectativa de utilidad o retorno, no se requiere que efectivamente se genere. 3) Riesgo: este elemento se analiza desde la intención del inversionista de acogerse a los beneficios de protección de un tratado, en el sentido de afrontar un riesgo de considerable envergadura, puesto que si la entidad del mismo fuera leve, se habría efectuado la inversión aun si dicha protección no existiera o no se pudiera hacer uso de la misma a través del arbitraje. 4) Compromiso: tanto el inversionista como la inversión deben tener un compromiso sustancial. Esta característica ha recibido críticas por considerarse un criterio subjetivo, dependiente de la posición de las partes. Si son grandes compañías o si se trata de empresas que están comenzando sus negocios; o si se trata de un país desarrollado y uno en vía de desarrollo. 5) Trascendencia de la inversión: esta debe ser significativa para el desarrollo del Estado receptor. Aquí se tienen en cuenta los motivos que el Estado destinatario contempla a la hora de aceptar la inversión.

Lo importante de estas precisiones radica en saber si se está frente a una inversión que encaje en el horizonte del TLC, para proceder, en caso necesario, a utilizar la protección que consagra el instrumento internacional.

Después de revisar la noción anterior, es importante concretar el concepto sobre arbitraje internacional de inversiones, para lo cual resulta pertinente recurrir a la definición de Omar García (2006), quien indica que se trata de «un mecanismo de solución de controversias legales relativas a inversiones entre el Estado anfitrión y un inversionista de otra nacionalidad».

El mismo autor señala que se excluyen de esta definición las disputas de naturaleza técnica, como por ejemplo en un contrato de construcción las diferencias entre las partes respecto a las dimensiones de unas tuberías. Tampoco se incluyen las diferencias que versen sobre materias de estricto comercio y, por último, los intervinientes deben ser un Estado y un extranjero pero no un Estado y sus nacionales. 
En teoría, esto parecería sencillo, pero de acuerdo con Gaillard (2007) la práctica ha demostrado que determinar si frente a un determinado asunto se puede recurrir $o$ no al arbitraje de inversión, como en el caso de ciertas situaciones en torno a cláusulas contractuales, implica adentrarse en un área muy controversial.

El asunto se vuelve aún más complejo cuando ciertas provisiones normativas de resolución de controversias contenidas en tratados de protección a la inversión están redactadas en forma abierta, pues se incluyen palabras como: todas o cualquier controversia relativa a inversiones puede ser presentada al tipo de arbitraje antes referido. Descifrar este tipo de cláusulas se ha convertido en un escollo para la práctica arbitral.

\section{ORÍGENES DEL ARBITRAJE DE INVERSIÓN}

La evolución de este tipo de arbitraje se ha desarrollado entre los dos extremos de la relación que obligatoriamente siempre están presentes: de un lado el interés del Estado receptor entendido como la búsqueda de su desarrollo y, del otro lado, el interés del inversionista extranjero, que con sus aspiraciones empresariales va en pos de obtener incremento en sus ganancias y de ensanchar sus campos de acción, etc.

Por la naturaleza de dichas relaciones se presentan disputas entre las partes que han venido manejándose de manera diferente a partir de consideraciones legales o teóricas (García, 2006). Un ejemplo de lo anterior es la denominada Doctrina Calvo que buscaba evitar la intervención europea en América, en los eventos en los que países del viejo mundo pretendían cobrar deudas públicas a las antiguas colonias. Esta doctrina puso de relieve que si los países europeos en sus relaciones recíprocas respetaban el derecho internacional y se abstenían de cobrar créditos y hacer reclamaciones privadas, utilizando intervenciones armadas contra los otros gobiernos, no había razón alguna para que no hicieran otro tanto con respecto a los Estados americanos (Monroy, 2011).

Se requería, de acuerdo con Calvo, que en los contratos suscritos entre Estados y ciudadanos o entidades de otro país se renunciara a la potencial protección que el país extranjero pudiera brindar a los inversionistas, quienes se comprometerían a sujetarse únicamente al derecho del Estado en el que se hacía la inversión. Se dejaba fuera la posibilidad de recurrir a instancias internacionales para dirimir conflictos de esta índole.

García (2006) señala que hasta 1959 un inversionista extranjero inconforme tenía dos opciones: demandar al Estado receptor en los tribunales locales o pedir protección a su propio país, lo que podría generar que ambos Estados negociaran o emprendieran una acción ante la Corte Internacional de Justicia o ante su organismo antecesor. 
De la misma forma, se aduce que en 1959 se creó un tratado de protección a la inversión extranjera entre Alemania y Pakistán, que marcó un hito a partir del cual se han pactado mas de dos mil tratados en este sentido y se han incluido, como en el caso del TLC entre Colombia y Estados Unidos, capítulos de protección a la inversión extranjera.

El 18 de marzo de 1965 el Banco Mundial creó el Centro Internacional de Arreglo de Diferencias Relativas a Inversiones Ciadi (Fernández, 2012), conocido en inglés como ICSID (International Centre for Settlement of investment Disputes), que se estructuró bajo la idea de fomentar las inversiones extranjeras en países en desarrollo, para lo cual se hacía necesario proporcionar un marco de estabilidad en torno a la solución de las controversias que en este plano pudieran llegar a surgir. Es oportuno anotar que el Ciadi (2012) registra que Colombia firmó dicha Convención en mayo de 1993 y la misma entró en vigencia para nosotros en 1997.

Varadí, Barceló III y Von Mehren (2006) reconocen al Ciadi como un escenario destacado en la resolución de disputas de inversión, incluso llegan a considerar que está siendo subutilizado precisamente por lo limitante de la naturaleza de sus partes, pues su acción se reserva solo a conflictos entre Estados y particulares de otro Estado.

Para recurrir a arbitraje ante el Ciadi es necesario que tanto el Estado receptor como el Estado de nacionalidad del inversionista hayan aceptado dirimir sus conflictos de inversiones en este escenario. En caso de que solo uno de los dos haya aceptado esta opción, se dispone de un mecanismo que permite arbitrar en Ciadi, siempre y cuando voluntariamente las partes implicadas lo hayan aceptado.

Para el caso colombiano, es importante puntualizar que el texto de nuestro TLC con Estados Unidos, en su Capítulo X Sección B Art. 10.15, prevé que los mecanismos de solución de controversias entre inversionistas y Estado son: consultas y negociación que pueden incluir a terceros y tienen procedimientos no obligatorios.

Ahora bien, si a criterio de una parte la controversia no puede resolverse mediante los mecanismos antes señalados, puede presentar su reclamación sometiéndola a arbitraje. Este arbitraje de acuerdo con el texto del TLC, se realizará con arreglo a las normas Ciadi y a sus procedimientos, aplicando igualmente la ley contenida en el TLC y en el Derecho Internacional.

Por su parte, Zuleta (2007) señala que el artículo 10.16 del referido tratado contempla la posibilidad para el inversionista de escoger entre diferentes opciones: Ciadi, las reglas de la CNUDMI (Comisión de las Naciones Unidas para el Desarrollo del Derecho Mercantil Internacional), o previo acuerdo de las partes cualquier otro escenario, por ejemplo la Corte de Arbitraje de la Cámara de Comercio Internacional. 


\section{RELACIÓN ENTRE TLC Y ARBITRAJE DE INVERSIÓN}

El arbitraje de inversión es, pues, una figura incluida en el TLC a la que se acude en casos de conflictos respecto a la inversión realizada por un extranjero.

Sin embargo, los movimientos internacionales de capital no se ven como algo nuevo o propio de ciertos regímenes. Sorensen (2008) aduce que dichos movimientos han sido una constante practicada tanto por gobiernos absolutistas como por gobiernos democráticos que buscan en el mejor de los casos «posibilitar el desarrollo de la productividad potencial de sus comunidades nacionales». Sobre la base de este postulado, se busca con los TLC y con el consecuente arbitraje de inversión favorecer los intercambios comerciales y, por ende, las inversiones.

Este empeño se ha visto plasmado en diferentes clases de instrumentos nacionales, como lo anota García (2006) quien se refiere a los denominados Tratados Bilaterales de Inversión TBI (BIT por su sigla en inglés), así como a los tratados multilaterales que abordan temas de inversión, ya sea en un ámbito regional, dentro de un tratado de comercio - como en el caso del TLC Colombia-EE.UU.-, los que se refieren a garantías contra riesgos no comerciales o los que crean centros para dirimir conflictos relativos a inversiones.

La relación estrecha entre los TLC, en nuestro caso el de Colombia-EE.UU., y el arbitraje de inversión radica en que, mediando la voluntad de las partes del aludido tratado, el Estado colombiano en busca de tener medios para poder financiar su desarrollo aceptó ciertas reglas en las que (con el interés de proteger la inversión de sus nacionales) Estados Unidos participó. La protección otorgada por Colombia se concretó en medidas como la implementación de los estándares mínimos de protección a la inversión, los cuales benefician a los inversionistas extranjeros.

De otro lado, esa relación se evidencia cuando se afirma que para que haya inversión extranjera se hace necesario hacer atractivo al país destinatario de la inversión y, para ello, sobretodo, en cuanto a lo que a países en vía de desarrollo se refiere, en concepto de Zuleta (2007), se requiere de la presencia de ciertos elementos que los inversores extranjeros examinan antes de proceder a actuar: la estabilidad económica, la estabilidad política, la seguridad física, la seguridad jurídica, la existencia de tratados de doble tributación y la existencia de tratados internacionales de protección a la inversión.

Por lo anterior, pensar en el TLC Colombia-EE.UU. nos lleva indefectiblemente a considerar la existencia del arbitraje de inversión, puesto que el primero implica movimiento de capitales y actividad de humanos que comprenden conductas de operaciones de mercado, que por su misma índole generan conflictos, y cuya solución está sujeta perentoriamente al segundo mecanismo mencionado. 


\section{DEFENSORES Y ADVERSARIOS DEL TLC Y DEL ARBITRAJE DE INVERSIÓN}

De una parte se afirma que si no se hubiese concertado el TLC, el comercio bilateral con los Estados Unidos caería en un 57.6\% (Ministerio de Comercio, 2013b); sin embargo, otros sectores de opinión cuestionan la viabilidad de las ventajas de este tipo de acuerdos y hacen especial énfasis en los efectos negativos tanto del tratado en sí como de sus derivados obligatorios, para nuestro caso el arbitraje de inversión.

Empezaremos por reseñar la posición del gobierno colombiano, que a través de su Ministerio de Comercio, Industria y Turismo (2013b) hace públicas las transformaciones que este TLC, desde su criterio, trae. Nos referiremos aquí a ejemplos de beneficios para la industria y el agro, toda vez que las contribuciones que el Tratado aporta, a nivel de derechos sociales, según este lado de la opinión, serán revisadas en un momento posterior.

Nuevos puestos de trabajo, crecimiento en la economía del país, reducción de la tasa de desempleo, preferencias arancelarias y el incremento en el 19\% de las inversiones extranjeras, son solo algunas de las ventajas que el Ministerio de Comercio considera que se obtendrán con la aplicación del TLC con Estados Unidos.

Los beneficios referidos por parte de este grupo de defensores desde el ámbito del gobierno son, entre otros:

- El crecimiento anual de la economía en Colombia y la reducción en la tasa de desempleo, pues se prevé la creación de 380.000 puestos de trabajo.

- Las preferenciasarancelarias del Aptdea no se perderán para Colombia. En consecuencia los sectores como las flores, confecciones, plásticos y manufacturas, así como tabaco y cacao obtendrán beneficios.

- Aumento del número de productos que Colombia exporta a los Estados Unidos.

- Aumento de la inversión extranjera en Colombia, superior al 19\%.

- Acceso inmediato de un gran número de productos colombianos al Mercado de EE.UU. Ampliación de ciertos sectores como las confecciones que generarán nuevas líneas de exportación.

- Mayor número de bienes provenientes de Estados Unidos, como materias primas y bienes de capital que no se producen en el país.

- Aumento en la competitividad nacional; posibilidad de ofrecer mejores precios a los consumidores; reducción de costos en la producción. 
- Las PYMES se verán beneficiadas por la reducción en sus costos de producción que traerá la reducción de aranceles. Además, se presentará una baja en los costos de actualización en el campo de la tecnología y, consecuentemente, mejorará su productividad.

- Ampliación de las oportunidades para el sector textilero nacional, sobre todo en confecciones y el sector de la moda. La industria del cuero y calzado se verá beneficiada por las preferencias arancelarias. Lo mismo se prevé para el sector de las grasas, especialmente las fabricadas a base de palma.

- El sector agrícola se beneficia con acceso real y protección a los productos sensibles. El campo de acción para productos nacionales como frutas, hortalizas, lácteos y cárnicos se ampliarán.

- Se mejoraron las condiciones de acceso al mercado de EE.UU. para productos como pastas, galletas, cacao, panela y hierbas aromáticas.

- En caso de competencia adversa para productos colombianos, se consagraron medidas como salvaguardias automáticas, plazos amplios de desgravación y plazos de gracia para agricultores colombianos, entre otras.

- Se consagraron mecanismos para que se agilice la admisibilidad de los productos colombianos en el mercado de EE.UU. para evitar que los requisitos tónicos, sanitarios y fitosanitarios se constituyan en impedimentos para el mercado de nuestros productos.

- No habrá barreras para el acceso de servicios al mercado desde Colombia hacia los EE.UU., esto mejora la competitividad, genera desarrollo y aumenta las exportaciones.

En el mismo sentido favorable al TLC, se han pronunciado quienes a pesar de reconocer que el derecho a la autonomía y a la autodeterminación son parte de la democracia, hoy la autarquía económica en un Estado es inconcebible, así como su desarrollo de forma aislada (Reisman, 2007). Por lo tanto, el único modo viable de subsistencia de los Estados desarrollados, o de aquellos deprimidos, es involucrarse en la economía internacional a través del comercio y de la inversión extranjera.

Acorde con lo anterior se encuentra la afirmación según la cual «la vida social se ha achicado y el destino de los pueblos se ha convertido en el destino del mundo globalizado» (Rueda, 2011).

Por su parte, una considerable porción del gremio de los profesionales del Derecho en Colombia - que se dedican al litigio en los temas económicos internacionales, en el comercio exterior, derecho aduanero, derecho migratorio y propiedad intelectualconsidera que el incremento de las inversiones extranjeras en nuestro país, a partir de la entrada en vigencia del TLC, es una oportunidad inigualable para la consolidación 
de sus áreas de trabajo y la proyección internacional de los abogados colombianos. Asimismo, señalan que las consultas sobre temas como medidas de defensa comercial, normas de procedimiento de origen o sobre arbitraje de inversión son cada vez mas frecuentes, lo que implica un reto para las firmas de servicios jurídicos que ahora deben expandir con mayor energía sus acciones hacia la formación multidisciplinar de equipos, hacia la capacitación jurídica y en idiomas de sus funcionarios, y hacia su participación activa en medios públicos en los que se ventile la normativa que cumpla con los aspectos internos del derecho doméstico, así como con las obligaciones derivadas de los tratados.

El campo de acción de estas firmas de abogados se extendió, lo que las llevó a incrementar la búsqueda de firmas homólogas en el exterior a fin de brindar una asesoría adecuada, no solo cuando ya se forme el litigio, sino desde el momento en que, con la entrada en vigencia del TLC, Colombia se hizo un país mas atractivo -o por lo menos así se buscó- para las inversiones extranjeras (Fierro, 2012).

En cuanto al arbitraje de inversión, se afirma en su defensa que su inclusión en nuestro TLC constituye, junto con otros factores como una economía y política estables, una forma de atracción de capitales extranjeros (Zuleta, 2007). Bajo esta visión, entonces, este mecanismo resulta positivo para el desarrollo de nuestro país.

Ahora bien, ¿qué sucede en el otro polo de la opinión?, ¿cuáles son los argumentos de los aquí llamados adversarios de este TLC? Bajo la mirada escrutadora de ciertos sectores, los TLC hacen parte de una dinámica propia del capitalismo cuyo proceso de acumulación está siempre sediento de obtener nuevas maneras de sustento. Se indica que los métodos utilizados para la obtención de este fin son múltiples y diversos, con el objetivo de seguir reproduciéndose, y que en ellos se atrinchera el sistema de los acuerdos comerciales como forma internacional de acumular capital (Regueiro, 2008).

Ahora bien, en este orden de ideas, el arbitraje de inversión, como creatura propia de los tratados bilaterales de inversión y de los TLC, está atado de manera inevitable a las prácticas internacionales de manejo de capitales extranjeros, y en esa medida se concibe como una forma de intervención que, con su aplicación, podría considerarse como contraria a la realidad y soberanía de los Estados (Gamboa, 2007). También se ha atacado a este mecanismo por considerarlo contrario a la Constitución de los Estados, transgresor de los derechos económicos de los ciudadanos y gestor de barreras a derechos fundamentales como el acceso a la justicia.

Desconfianza, esa es la sensación que para algunos producen los TLC y todo lo que ellos impliquen. En Latinoamérica, y desde una óptica de un sector considerable de ciudadanos del común, estos tratados se ven como medios para abrir los mercados domésticos a bienes y servicios provenientes de los Estados Unidos, que acaparan no solo las potenciales oportunidades de los nacionales, sino que incluso tocarían mercados que desde antaño eran suplidos con productos locales. 
Esta manera de manejar el mercado, según Regueiro (2008), garantiza el monopolio, puesto que mediante una legitimación, a través de un tratado, se busca llegar a acuerdos con países a los que puedan moldear y que se ajusten a sus necesidades de acumulación y por ende de reproducción del poder.

Sobre el caso específico del arbitraje de inversión, algunos perciben que el manejo de capitales extranjeros se basa en prerrogativas que el TLC con Estados Unidos ha concedido a las inversiones de dicho país, que son consideradas como discriminatorias respecto de la parte colombiana, pues están diseñadas para proteger al inversionista y a sus rendimientos (Zuleta, 2007).

Otro punto en contra del arbitraje de inversión es la posibilidad de confusión que se podría presentar en torno a quién tiene realmente la obligación de prestar, por ejemplo, un servicio público domiciliario, en el evento en que el TLC proteja una inversión destinada a participar en dicho sector. Podría presentarse el caso del desplazamiento de la responsabilidad del Estado frente a su obligación de proteger y garantizar los derechos de los habitantes de su territorio (Kiebraum, citado en Zuleta, 2007), cuando en realidad es el Estado y no el inversionista quien tiene esta obligación.

En el ámbito concreto de Colombia, la percepción de efectos considerados nocivos luego de la entrada en vigencia del TLC ha producido movimientos sociales que ejercen abierta oposición al TLC, como el denominado RECALCA (Red Colombiana de Acción frente al Libre Comercio, 2013) del departamento de Bolívar. Según su criterio, luego del TLC las exportaciones de dicho departamento en el primer semestre de 2012 fueron de 1.725 millones de dólares aproximadamente, cifra que comparada con la de 2011 disminuyó en un $7 \%$. De allí —entre otros hechos señalados - concluyen que las tan anunciadas bondades de este Tratado no eran ciertas, máxime cuando se afirmó, según lo indican, que con el TLC el acceso al mercado estadounidense, que cuenta con 300 millones de consumidores, sería ilimitado para la industria colombiana, que incrementaría sus exportaciones, pero los guarismos citados lo desmienten.

\section{CONCLUSIONES}

La realidad internacional requiere que los Estados interactúen en mayor o en menor grado, pero resulta imposible mantenerse al margen de la actividad de los demás países y organismos internacionales. A pesar de las diferentes posturas respecto de la posibilidad de acercarse a mercados e inversiones extranjeras, lo cierto es que en el mundo de hoy los tratados de inversión y los de libre comercio están a la orden del día.

El TLC Colombia-Estados Unidos es una realidad y su contenido y la ejecución del mismo repercuten de forma positiva y negativa en la vida de nuestro país. Dentro de sus 
apartados, este TLC, al incluir el arbitraje de inversión, posibilita que el capital extranjero pueda ser invertido en Colombia, puesto que sus titulares buscan seguridad, la cual ven reflejada entre otros factores en la claridad de poder recurrir a una administración de justicia diferente a la del país destinatario de su inversión, dado el recelo que existe respecto a situaciones cercanas a la expropiación en ciertos Estados.

Será necesario preguntarse para el caso del arbitraje de inversión en específico si ¿la no presencia de capital extranjero afectaría la garantía de los derechos sociales y económicos de los colombianos?, ¿será que las ineficiencias del Estado respecto de la satisfacción de los derechos hace necesaria la participación de inversionistas de fuera? Si esto es así, se haría necesario que, a causa de la posible inoperancia del sistema judicial colombiano en cuanto a inversiones extranjeras, este deba ser reemplazado por un ente internacional como el Ciadi, tal como lo posibilita el Tratado? ¿Será que las decisiones allí tomadas están en coherencia con la realidad de los derechos económicos y sociales de los colombianos?

Los argumentos de quienes defienden el TLC $y$, por ende, la necesidad de proteger las inversiones con el arbitraje de esta índole, estarán enmarcados en la defensa de la globalización y en la necesidad de la garantía del libre flujo de los capitales. Por su parte, los detractores invocarán la soberanía y el afán del capitalismo por nutrirse y multiplicarse a partir de la intromisión en los Estados.

Tanto el TLC como el arbitraje de inversión tienen amigos y enemigos; sin embargo, más que la discusión respecto de quién tiene la razón, lo que resulta trascendental para nuestro país es logra armonizar la aplicación de estos mecanismos -que innegablemente proporcionan ciertas ventajas al país pero también afectan sectores de la economía - con los derechos económicos y sociales de los colombianos, para lo cual debe abordarse en un estudio futuro. 


\section{REFERENCIAS}

Correa, J. (2006). Historia de un proceso que tardó 7 años. Revista Portafolio. Recuperado de: http://www.portafolio.co/negocios/historia-un-procesoque-tardo-7-anos

Fernández, E. (2010). La realidad del arbitraje de inversión desde la perspectiva latinoamericana. El arbitraje Interno e Internacional en Latinoamérica. Regulación presente y tendencias del futuro. Bogotá: Universidad Externado de Colombia.

Fierro, J.M. (2012). Tratados de Libre Comercio: El gran reto para los abogados colombianos. Ámbito Jurídico, p.10

Gaillard, E. (2007). The Effect of Broad Dispute Resolution Clauses in Invest Treaty Arbitration. En Arbitraje internacional. Tensiones Actuales. Bogotá: Legis.

García, O. (2006) Nociones Básicas del Arbitraje Internacional de Inversiones. Recuperado de: http://www.bg-consulting.com/basic.pdf

Gamboa, N. (2007). La inmunidad soberana de jurisdicción en el arbitraje comercial internacional: evolución y actualidad. Bogotá: Universidad del Rosario.

ICSID. (2012). List of Contracting States and other Signatures of the Convention. Recuperado de https://icsid.worldbank.org/ICSID/FrontServlet?request Type $=$ ICSIDDocRH\&actionVal=ShowDocument $\&$ language $=$ English

Jiménez, L. (2012). Los impactos negativos del TLC con Estados Unidos en la estructura productiva en Bolivar. RECALCA, Red Colombiana de Acción frente al Libre Comercio. Recuperado de: http://www.recalca.org.co/los-impactosnegativos-del-tlc-con-estados-unidos-en-la-estructura-productiva-enbolivar-los-hechos-nos-dan-la-razon/

Ministerio de Comercio, Industria y Turismo de Colombia. (2013a). ABC del TLC. Recuperado de: https://www.mincomercio.gov.co/publicaciones. php?id=637

Ministerio de Comercio, Industria y Turismo de Colombia. (2013b). Texto Final del Acuerdo. Recuperado de: http://www.tlc.gov.co/publicaciones.php?id=727

Ministerio de Comercio Exterior y Turismo de Perú. (2013). Acuerdo de Promoción Comercial Perú-Estados Unidos. Recuperado de http://www.acuerdoscomerciales.gob.pe/index.php?option $=\mathrm{com}_{-}$ 
content $\&$ view $=$ article $\&$ id $=48 \% 3$ Alo-que-debemos-saber-de-lostlc\&catid $=44 \% 3$ Alo-que-debemos-saber-de-los-tlc\&Itemid $=78$

Monroy, M. (2011). Derecho Internacional Público. Bogotá: Temis.

Regueiro, L. (2008). Los TLC en la perspectiva de la acumulación estadounidense. Visiones desde el MERCOSUR y el ALBA. Buenos Aires: CLACSO.

Reisman, M. (2007). Reflections on Economic Development, National Sovereignty and International Arbitration. En Arbitraje Internacional. Tensiones actuales. Bogotá: Temis.

Rueda, P. (2011). Sociología del Derecho. Lima: Universidad San Martín de Porres.

Silva G. (2002). Sobre el objeto, las fuentes y el oficio de la sociología jurídica. Una perspectiva interdisciplinaria. Bogotá: Universidad Libre.

Sorensen, M. (2008). Manual de derecho internacional público. México: Fondo de Cultura Económica.

Varadí T., Barceló III J y Von Mehren. (2006). International Commercial Arbitration. A Transnational Perspective. St. Paul MN: Thomson West.

Zuleta, E. (2007). El arbitraje de inversión en el Tratado de Libre Comercio suscrito entre Colombia y Estados Unidos. En Arbitraje Internacional. Tensiones actuales. Bogotá: Legis. 
